\title{
Service Pyramid Concept of Knowledge Intensive Business Services in the Small and Medium Sized Enterprises Sector
}

\author{
Sándor Nagy \\ Institute of Business Sciences \\ University of Miskolc \\ Miskolc, Hungary
}

\begin{abstract}
The activity of service companies is more complex today than before the use of Information and Communication Technology (ICT) became widespread in business. Fewerservice companies can be found on the market based solely on physical customer interaction; however, they have beenreplaced with standardized and automated services. This structural change can be observedparticularly among Knowledge Intensive Business Services (KIBS) companies where the use of ICT is not simply a market requirement, but a competition tool, as well. Without the application of any ICT instrument, a KIBS company could not meet market expectations, and furthermore, business developments are mainly ICT-based. On the other hand, companies need to develop their businesses more and more, as KIBS companies which are not able to differentiate themselves as trustworthy on the business services market will disappear. 'Just another business service company' cannot really sell today. This is applicable to a greater extent to Small and Medium Sized Enterprises (SME), where ICT has opened market opportunities that have never existed for them before. The aim of this paper is to highlight the new features of KIBS business activities inthe SME sector and the related research questions.
\end{abstract}

Keywords-knowledge intensive business services; information and communication technology; small and medium sized enterprises; productisation; service product; service pyramid

\section{INTRODUCTION}

The network-like allocation of value creation in the open global economy contributed to the replacement of labourintensive activities with knowledge intensive activities in the developed countries. This can easily be observed in the national statistical databases, but research programs and studies also deal with the contemporary economic questions of knowledgebased products and services. Derived from the most important features of services, this sector is highly receptive for technological innovations, which makes it a rapidly changing business area where prompt market reactions mean strategic advantage. During the last two decades, new companies emerged and grew to a global level based on Information and Communication Technology (ICT) innovations and finally they made available several high value business services for Small and Medium Sized Enterprises (SME), as well. In this paper a new service pyramid concept will be presented which can provide solutions for Knowledge Intensive Business Service (KIBS) companies to synthesize new features of services and the advantages of ICT spread in the SME sector in order to develop a successful market strategy.

\section{NEW FEATURES OF SERVICES}

Earlier theoretical works determined services according towhat they are not (they are not agriculture and not industry) and their most important feature was that the production and consumption inseparably coincide with each other, while in case of the physical goods, a lot of time may pass between production, sales and consumption. The first modern approaches toservices were published after the 1950s, whenthe increasing role of complex services becamea main feature of the capitalist economies, which is the next stage in the economic development of industrial countries. Beside this tertiarisation in the developed economies, research isdiscovering new characteristics of services, indicatingthat serviceswill increasingly behave as physical products: in contrast with the earlier scientific view, more and more services can be kept in stock and can be mass-produced and mass-consumed. These factors point to a redefining of the economic role of services. Of course, it could be supposed that some services simply become physical products. ${ }^{1}$

Moreover, it can decreasingly be said that services only adoptto innovation. This finding come from analyzing Research and Development (R\&D) expenditures, but this was not obviously the accurate conclusion. As the interpretation and classification of R\&D expenditures of service companies was not quite precise - people both in surveys and in accounting basically were not sure what can be regarded as research activity in relation to service- research that operateswith thesenumbers may mislead with its conclusions that service companies do not innovate. In many companies, innovation costs are classified as $\mathrm{R} \& \mathrm{D}$ when they are linked with physical products or when outputs of developments are physically embodied. Empirical results have shown that service innovation is a hardly recognizable activity for companies [4]. On the other hand, in new publications, $R \& D$ expenditures of the service sector are similar to those ofthe process industry in developed countries. In the service sector, innovations are hard to reconcile with the traditional definitions for the following reasons:

${ }^{1}$ It is interesting that in contrast, physical products incorporate more services than before. 
- they do not obviously result in new technologies or new technical solutions,

- they are mostly not tangible, which make them hard to measure,

- service innovation sources often come from customer relationships,

- they are combinations of in-house and exteriorfactors

- they are more difficult to protect with patents.

These problems require a wider interpretation of innovation in the service domain, where not only technological advances but also changing customer needs drive developments, and it is sourced in market cooperation.

Current service developments are clearly aimed to eliminate, or at least reduce, the inseparable nature of service delivery and consumption. With this, enterprises can significantly expand (or even wholly eliminate) the time constraints arising from inseparability. For example, if banking services can only be accessed duringopening hours, then this causes a large number of lost market interactions, while the ATMs (cash dispensers) or online banking services offer virtually non-stop availability. (The reduction of operation costs is an additional benefit.)

Research has shown that the use of information technology improves productivity and advancesglobalization in the service sector. In recent decades the global trade of services grew more intensely than the trade of goods, making the former scientific approach disputable. Researchers traditionally used to believe that services cannot be traded. This approach was first criticized already in the 1980s. Today, the global trade of services hardly needs to be proven; rather,it causes challenges to governments (due to e.g. taxation issues). Thus, services have become as globalized as physical products; this is mainly driven by ICT developments, knowledge transfer and innovation. In the last two decades, the spread of ICT catalyzed this process by offering new business operation models to service enterprises.

However, due to service development, companies have to face new challenges such as diversified needs of customers. Although service providers are interested in standardization and automation, ICT applications enable and allow them to offer solutions that satisfy the customers' individual needs,also. Similarly to the processing industry, mass production is combined with mass customization in the services market as well.

The idea behind mass customization is to be able to deliver services tailored to individual needs, while keeping the effectiveness and cost benefits of mass production. Considering the traditional characteristics of services, it can be observed that mass customization may ease the disadvantages of services: it reduces inseparability, helps systemize heterogeneity, makes tangible the intangible, improves expected quality and, where necessary, promotes long-term customer relationships. (As a relatively new phenomenon, customers are actively involved not just in the production but in the distribution process, as well.)
In order to fit in the market expectations and to utilize the spread of ICT in business use, service companies could innovate with new and commercially valuable goods which are more tangible. In the literature,related terms can be found as commodification and productisation referring to the activity where service companies provide more product-like solutions through systemization of their components. The first need for systemization emerged in the field of marketing, but now it is widespread. Newer research isfocusing mainly on formal service development processes with diverse stages (from idea generation to commercialization), which approach comes from the domain of manufacturing. Another study method is to model the service, which has a wider view and has the benefit of combining unique services with standard services based on the output perceptions of the customer. Modeling is built on the experiences of service processes as prerequisites with three equally important components:

- the service concept and structure based on customer needs,

- the service process as the prototype, and

- theservice system which involves the resources to deliver [6].

As stated by the supporters of the modeling method, it allows developers to focus on customer needs. Problems emerge from gathering and selecting relevant customer information as an input to the model.

Despite the advantages of productisation,there are obstacles on the market. Companies are concerned about converting their knowledge into tangible products as they could be copied and stolen without any difficulty. In non-academic publications, consultants highlight the fact that complex knowledge products are not attractive to imitate and they are encouraging companies to use productisation bravely.

\section{INFORMATION AND COMMUNICATION TECHNOLOGY IN KNOWLEDGE INTENSIVE BUSINESS SERVICES}

The above changes can also be observed in knowledgeintensive activities. The term KIBS in general refers to knowledge-intensive inputs provided for the business processes of business organizations, including both private and public organizations. Consequently, KIBS are not goods for private consumption. The term was first introduced by Miles in the academic literature, who proposed to distinguish between two groups in the KIBS sector: traditional professional services ( $\mathrm{P}$ KIBS) and advanced technology-based services (T-KIBS). The P-KIBS group includes traditional professional services that intensely apply the advanced technology (business and management services, legal and accounting activities, market research, etc.), while T-KIBS services are more closely related to the ICT sector, meaning that they are mainly focused on providing advanced technology-based services (IT services; engineering tasks; R\&D consulting, etc.) [2].

The KIBS sector presented strong growth, and European studies have revealed several driving factors of this[1]:

- companies buy more solutions from outside their organizations (outsourcing and offshoring), 
- increasing demand for technological knowledge (especially ICT related ones),

- increasing demand for specialized knowledge of social, administrative, and regulatory issues (compliance),

- internationalization and globalization issues,

- a growing role of services and intangible elements in production and in products,

- agrowing number of knowledge workers in labour markets.

The economic role of the KIBS sector is a central question in all academic publications as it emerges in the knowledge and innovation processes nationally and globally where KIBS companies are strong partners for other organizations. In this relation effective business services are focused on interaction between providers and customers in order to emphasize the connection in delivering processes. Keeping the traditional view of services where customers actively participate in the service production processes, co-production means

- interactivity in knowledge transfer and in learning,

- a tailor-made approach, where

- services necessarily start from scratch [6].

Co-production is essentially different from routine purchases, because during this process a client accesses to the expertise of the provider, rather than just gettinga commodity. This ledresearchers to debate standardization and automation opportunities in the KIBS market, but in this research concept it is not necessarily the only conclusion. Rather, it is better to perceive multiple ways to deliver a KIBS service while both customized and standardized solutionscan be observed. When it is proper to use a tailored approach or standardization isestablished as a more appropriate research question.This perception could much better explain how KIBS companies can utilize the penetration of new technologies.

ICT plays an important role in the life of KIBS companies, which can be explained by its digital nature, since ICT enables these companies to record, process, store and distribute the information which play vital role in producing the output of KIBS. Thus, the ICT enhances the classic service provisioning function by supporting operational processes, reducing costs and increasing the speed of operation. The integration of ICT developments into business processes has brought significant progress in collecting, storing and distributing business knowledge. As knowledge is the most important property for KIBS companies,howICT could help them use their knowledgeis a central question, whether that knowledgeis in the employee's head or in documents. This process is called knowledge management, where knowledge could be differentiated as

- explicit, which is formal and independent from individuals (andcan be copyrighted), or

- tacit which is informal and dependent on individuals (andcannot be copyrighted).
With the spread of the ICT, a huge volume of explicit knowledge has become available for a wide range of companies - more than ever before. Considering the role of ICT in knowledge management, the companies' aim is to convert tacit knowledge into explicit knowledge as much as they can. This often depends on the organizational culture. By formalizing the knowledge, KIBS companies advance the knowledge transfer which could be realized

- in customer interactions,

- through in-house relations,

- in sectorial interactions.

In addition to improving operations, the spread of ICT greatly promotes the opening and developing of new markets, because it can reduce the high transaction costs of knowledgeintensive activities. Some new KIBS services have appeared in the markets which have changed the opportunities of SME sector: certain services, which were previously overpriced, have become affordable for SMEs, and new services have also appeared. For example, it was not possibleearlier for a small company to plan and execute a targeted international advertising campaign. These days it is quite easy to do research in marketing databases and to set up fine-tuned campaigns as numerous companies offer real-time advertising services online for a relatively low price. Furthermore, instead of human agents, SME companies work with scheduled software workflows such as robots.As businesses apply ICT tools to support more and more business processes, the range of affordable KIBS services and mass customized services expands, since digitalization offers more opportunities for innovation. In this way, small organizations can have access to highly value-added inputs, which greatly improves their innovation capabilities, and, in turn, market competitiveness even at global level.

Thus, the spread of ICT has brought geographical changes as well, since it eases the distribution of KIBS services, which may balance spatial inequalities and enable clients to access KIBS services irrespective of their geographical location. Resulting from this, KIBS service providers which have wide market coverage can operate not only in big cities, but can serve their clients from relatively peripheral areas. This phenomenon can be observed globally. The spread of ICT also supports the cooperation between KIBS companies physically located far away from each other, enabling the creation of new types of inter-organization collaborations and networks. The development and the possible innovation respectively of a given KIBS activity or of a KIBS company obviously are not so evident, because the necessary information and skills are still focused onthe relevant central economic areas, althoughto a lesser extent. ${ }^{2}$

\footnotetext{
${ }^{2}$ As the information required for KIBS related developments is digitalized and uploaded to the internet, the physical location of a KIBS company becomes less important. Due to the general cost reduction endeavors, the number of personal meetings between stakeholders in the KIBS sector has largely dropped; they may meet personally only a few times a year. For instance, broadband internet access enables webinars (seminars broadcasted via the web), an increasing portion of the literature is available online, and developers can also have online access to databases. Metropolitan headquarters are oftenmaintained for prestige reasons only, in many cases just as a virtual office.
} 
The phenomena outlined above opens up entirely new prospects in smaller economies, as well, because SMEs can have a more balanced opportunity in market competition, which pushes companies to innovate, giving a new boost to their efficiency. Now ICT and the internet are not about simply having a website for KIBS companies; it is more about having an effective digital presence.

\section{Changes in KNowledge InTEnsive Business SER VICES CONCEPTS}

Revealing structural and organizational changes and their triggersin the KIBS sector could lead to a better understanding of knowledge-based economies and globalization, where scientific concepts are focused on the fact thatthat knowledge has an increasing role in creating the economic value. It could also help policymakers work out regulations not only for national development, but the international trade, as well. During the last few decades the content of the knowledgeintensive work has changed, as organizations require more and more complex and prompt solutions from business service companies. This indicates parallel changes in service developments, where companies try to find cost effective answers for customer needs.

Regarding the KIBS sector, not only fast volume growthcan be observed, but animprovement in quality, as well, which comes mainly from

- development of their clients,

- a growing proportion of outsourced complex business works,

- development of knowledge-based societies,

- increasing regulations,

- internationalization and globalization,

- technological innovations.

The general sector-level impacts of ICT on services, from a scientific point of view, can be studied sooner in case of KIBS services, because the knowledge-intensity puts these companies onthe leading edge in adaptation to changes. KIBS enterprises are open to accepting ICT-related innovations and, equally importantly, they are involved in significant innovation activities. Given that KIBS companies which operate on the SME market are heavily pushed to improve their efficiency, it may be said that the spread of ICT is a great opportunity for them to both gain new markets and enhance their productivity.

ICT is assisting KIBS companies to codify certain parts of their knowledge and also helps them gather information about the relevant market cost-effectively with online research tools for sales and innovation purposes, serving several functions:

- multiplying occasions to get sales leads,

- strengthening and automating customer relationship management,

- providing a source forgathering information about customer demand and market competition to innovate,
- using online tools to develop more efficient workflows, and

- Achieving spatial independence.

The KIBS-related changes listed in the previous sectionscan easily be seen in the SME sector when observing their impacts on the service concepts of KIBS companies. This approach could be considered a proper research methodology, because in this research it allows one to reveal casual relationships. These trends have been integrated in the service provision concepts and are fundamental parts of the strategic planning to such a degree that failure to consider these would be a competitive disadvantage. Nowadays in the SME sector there is an increasingly lower demand for business services that are based on classic organizational and operational principles. The reason is simply because companies on the side of clients are changing in their behavior when operatingwith a KIBS company. This starts with the search phase, when they are looking for solutions on the market. Previously, decision makers initially asked around in their narrow environment, or there were printed and periodically updated catalogues to find a business provider; now nearly every search starts in a web browser.

Before introducing the new service concept, it is useful to compare the relevant features of the previous traditional (classic) KIBS services and the currently identifiable versions.

Based on the earlier theoretical works of services in Table 1 , seven main features have been highlighted in order to draw attention tothe key characteristics of KIBS. Each feature could help KIBS companies as important innovators in service innovations identify developing areas. The comparison begins with splitting production and consumption, which introduces other new features because by their separation, the phenomenon of intangible goods arises, where other advantages could be derived: by digitalizing a service, it could be disconnected from humans on the provider side, whereby the possibilities of the digital worldcan be utilized. Here, the geographical and time limits disappear, which opens new opportunities for innovation. From the operational and policymaking points of view, the decreasing transaction cost could be a significant change, as it is an important factor both in micro and macro levels in economies.

TABLE I. FEATURES OF CLASSIC AND NEW KNOWLEDGE INTENSIVE BUSINESS SERVICES

\begin{tabular}{|l|c|c|}
\hline \multicolumn{1}{|c|}{ feature } & classic KIBS & new KIBS \\
\hline \hline $\begin{array}{l}\text { production and } \\
\text { consumption }\end{array}$ & inseparable & separable \\
\hline transaction costs & high & low \\
\hline uniqueness & customized, unique & $\begin{array}{c}\text { customized, unique } \\
\text { and mass } \\
\text { customization }\end{array}$ \\
\hline geographical location & centers & anywere \\
\hline access to SME sector & limited & limitless \\
\hline innovation & $\begin{array}{c}\text { mainly user, } \\
\text { catalyzing other } \\
\text { innovations }\end{array}$ & $\begin{array}{c}\text { user, catalyst, and } \\
\text { important innovator }\end{array}$ \\
\hline trade & cannot be traded & could be traded \\
\hline
\end{tabular}

- eases recognizing and adopting external developments, 
In order to access the SME sector as much as possible and to achieve spatial independence, KIBS companies could focus on mass customization as well,in addition to the fully customized versions. Thus, the new service concept derived from the characteristics described above is also shown in Fig. 1.

Fig. 1 demonstrates that due to the changes identified in Table 1, the new concept of KIBS services can be recognized as a pyramid, where benefits related to the spread of ICT are apparent.
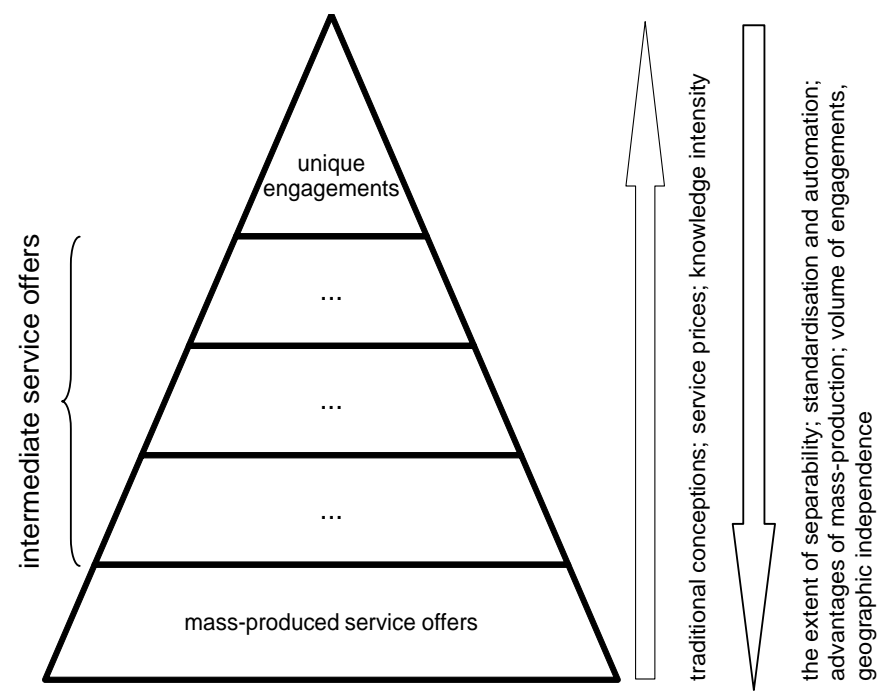

Fig. 1. Pyramid service conceptions of Knowledge Intensive Business Services.

The interpretation of the offering pyramid of KIBS services should start from its both ends: the bottom of the pyramid represents mass supply, while the top refers to absolutely customized services. Between the two extremes, there is an intermediate supply, which becomes more tailored as one movestowards the top of the pyramid. Consequently, the benefits of ICT (in terms of mass service delivery, standardization, automation and new types of services) impact the services at the bottom of the pyramid. As one movesdownwards from the top of the pyramid, services act more like a product, while those located in the top of the pyramid can be interpreted in the classic way.

In this research the 'service concept' is seen as a high-level and more general term, compared to the term of 'business model'. One maysay the business model can give operative tools that help implement the strategic service concept. KIBS service concepts can become a successful market strategy when a company is able to associate it with a logical, consistent, original, hard-to-copy business model.

Just asversioning is a well working business strategy for designing a product line of information goods, the service pyramid concept is a similarly proper approach for KIBS companies. Service pyramids let the service provider recommend different offers at a different level of complexity. KIBS companies are originally focused on providing complex and high quality version services. In a business manager's mind, a typical KIBS company is visualized as a wellfashioned, highly professional person, who is present himself in the manager's office and works hard with him to solve difficultbusiness problems. It is generally equal with the offer of any newly opened KIBS company. With service pyramids, a KIBS company usually creates the high-quality version first, and then as a top-down method they could subtract value from it to get lower-level services, which could be inserted in their product line as mass-market service products [5].

Additionally,it can be observed that in this complex system of service pyramids, companies can use modularity to develop new services. In the literature, modularity is presented as a design strategy that can stimulate market success and innovation mainly in ICT relation.

Modularity means a stable and clear architecture (both vertically and horizontally) with well-defined operation functions that reduce costs and decrease the uncertainty of adhoc work. Overall, modularity can be introducedinto services based on systemization, which helps moderate the disadvantages of heterogeneity. Service modularity is not only a source of effective operation but of a successful competition strategy, as well, where there is huge space for differentiation, especially in this intermediate time of new service strategies.

Note that in this perspective of KIBS services; they are similar to information products, as customers must experience themto value thembefore they decide to buy, so theycan be named 'experience goods' as well. For SME companies, advertising their KIBS services in a certain market does not mean getting clients directly from this promotionalactivity. As KIBS services are highly complex intangible goods, their qualities are not easy to explain to the customer simply throughadvertisements [3]. Actually, the successful advertising strategy for KIBS companies is not only about concluding a final contract, as it could be considered nearly impossible. Who will engage a tax advisor to harmonize a company's tax structure just because of their billboard? Advertising is rather about thinking in a big and subtle network of marketing tools and channels. High professionals traditionally have to build their reputations on the market, which helps them get through the first sales obstacles originating from information asymmetry and risks of fears of the customers. Building reputation is about widely communicating business results, goals and merits etc., which means sharing information with customers and building a closer relationship to eliminate risk from the first business relationship. And for communication in business to business (B2B) relation, the ICT is the main (but, of course, not the only) channel to send out messages today.

\section{CONCLUSIONS}

It is put forwardthat ICT is a great help for KIBS companies in obtaining new customers, retaining old ones, selling more, and improvingand innovating services. Changes on the markets make it harder for companies to use the relevant information while the importance of tacit knowledge is rising. This all stimulates the combination of external and internal knowledge in SME organizations which providenew possibilities for KIBS companies with a high competition level. Moreover, since only a few start-ups survive, KIBS companies 
need to find new, profitable ways to innovate services utilizing the standardization and automation advantage of the trend that services tend to be rather intangible products.

The scope of this paper does not allow a detailed description of the KIBS service pyramid concept presented inFig. 1, but this was not the goal of this research. The objective here is to highlight a research direction that is worth following in order to have a better understanding of the subject matter. The short history of research into knowledge-intensive business services has some very exciting questions left unanswered, which will be answered in the course of further research. For example, it is important to collect some empirical evidence about organization sizes, because the new KIBS service pyramid concept described here may effectively impact the SME sector in the near future.

As a next research steps it is neededto set up relevant KIBS clusters internationally (in developed and emerging markets) to see how these companies are utilizing the service pyramid concept and productisation in their market strategies (between leaders and followers), then benchmark their business performance with the market and with each other. This could give empirical evidence for the effective use of the service pyramid concept, both ata micro and macroeconomic level. Itis also expected that additional research areas will emerge, especially regarding the process of service productisation.

\section{REFERENCES}

[1] EMCC, European Monitoring Centre on Change, "Sector futures - The knowledge-intensive business services sector," European Foundation for the Improvement of Living and Working Conditions, Dublin, 2005.

[2] I. Miles, "Knowledge Intensive Business Services: Prospects and policies," Foresight 7(6), pp. 39-63, 2005.

[3] C.C.J.M. Millar, and C.J. Choi, "The innovative future of service industries: (anti-) globalization and commensuration," The Service Industries Journal, Vol. 31, (1) pp. 21-38, 2011.

[4] F. J. Mosoniné, M. Tolnai, and A. Orisek, Research and development and innovation in the service sector. Kutatás-fejlesztés és innováció a szolgáltatási szektorban. Nemzeti Kutatási és Technológiai Hivatal, Budapest, 2004.

[5] C. Shapiro, and H. R. Varian, Information rules: a strategic guide to the network economy. Harvard Business School Press, Boston, 1998.

[6] K. Valminen, and M. Toivonen, "Seeking efficiency through productisation: a case study of small KIBS participating in a productisation project," The Service Industries Journal, Vol. 32, No. 2, pp. 273-289, 2012. 